\title{
Editorial
}

Nephrology

\section{Meet the Twins: Intradialytic and Interdialytic Hypertension}

\author{
Panagiotis I. Georgianos ${ }^{a}$ Rajiv Agarwal ${ }^{\mathrm{b}}$ \\ ${ }^{a}$ Division of Nephrology and Hypertension, 1st Department of Medicine, AHEPA Hospital, Aristotle University of \\ Thessaloniki, Thessaloniki, Greece; ${ }^{\mathrm{b}}$ Department of Medicine, Indiana University School of Medicine and Richard L. \\ Roudebush Veterans Administration Medical Center, Indianapolis, IN, USA
}

Intradialytic hypertension reflects the "paradoxical" rise in blood pressure (BP) during or immediately after dialysis that contrasts with the typical fall of $\mathrm{BP}$ in response to ultrafiltration [1]. Intradialytic hypertension is reported to occur in approximately $10-20 \%$ of dialysis treatments, but the reproducibility of this phenomenon and the exact prevalence of "persistent" intradialytic hypertension remains unknown. In the absence of universally accepted diagnostic criteria, one definition of intradialytic hypertension is a rise of $\geq 10 \mathrm{~mm} \mathrm{Hg}$ in systolic BP (SBP) from pre- to postdialysis in at least 4 of 6 consecutive dialysis sessions [1]. In light of recent cohort studies showing that hemodynamic response to ultrafiltration displays a U-shaped association with mortality, patients experiencing consistently a rise in BP from preto postdialysis appear to carry a higher mortality hazard. The exact mechanisms mediating these adverse effects of intradialytic hypertension remain elusive.

One plausible explanation for the heightened mortality hazard attributable to intradialytic hypertension could be the persistence of higher BP loads during the out-of-dialysis period. This notion is supported by an earlier case-control study that compared 44-h interdialytic ambulatory BP levels between 25 patients with intradialytic hypertension

\section{KARGER}

(C) 2018 S. Karger AG, Basel

E-Mail karger@karger.com

www.karger.com/ajn (defined as rise of $\geq 10 \mathrm{~mm} \mathrm{Hg}$ in SBP from pre- to postdialysis in 4 of 6 consecutive sessions) and 25 age-, sex- and diabetic status-matched controls without intradialytic hypertension [1]. Mean 44-h interdialytic ambulatory BP was by $13.0 / 5.5 \mathrm{~mm} \mathrm{Hg}$ higher in patients with intradialytic hypertension than in controls without intradialytic hypertension (44-h SBP: $155.4 \pm 14.2$ vs. $142.4 \pm 16.5 \mathrm{~mm} \mathrm{Hg}$, $p=0.005 ; 44$-h diastolic BP: $82.4 \pm 10.8$ vs. $76.9 \pm 8.6 \mathrm{~mm}$ $\mathrm{Hg}, p=0.05$ ) [1]. In a subsequent case-control study from the same research group, it was shown that patterns and rhythms of interdialytic BP differ between patients with and without intradialytic hypertension [2]. Among patients with intradialytic hypertension, the slope of SBP change was negative $(-0.3 \mathrm{~mm} \mathrm{Hg} / \mathrm{h})$ during the first $24 \mathrm{~h}$ elapsed from dialysis, but positive $(+0.3 \mathrm{~mm} \mathrm{Hg} / \mathrm{h})$ during the dialysis-off day. By contrast, control patients without intradialytic hypertension displayed a gradual increase in SBP during the entire 44-h interdialytic period with a slope of $+0.6 \mathrm{~mm} \mathrm{Hg} / \mathrm{h} \mathrm{[2]}$. However, compared to controls, the average 44-h intradialytic ambulatory SBP was once again higher by $12.3 \mathrm{~mm} \mathrm{Hg}$ in those with intradialytic hypertension (44-h SBP: $155.4 \pm 14.2$ in those with intradialytic hypertension versus $143.1 \pm 16.5 \mathrm{~mm} \mathrm{Hg}$ in controls, $p=$ $0.008)[2]$. 
In this issue of the American Journal of Nephrology, Bikos et al. [3] report the results of a larger case-control study enrolling 41 patients with and 82 controls without intradialytic hypertension matched in a 1:2 ratio for age, gender, and dialysis vintage. Intradialytic hypertension was defined as a rise in SBP from pre- to postdialysis of $\geq 10 \mathrm{~mm} \mathrm{Hg}$, but the definition also required a postdialysis SBP $>150 \mathrm{~mm} \mathrm{Hg}$. Both cases and controls underwent 48-h brachial and aortic BP monitoring with the Mobil$\mathrm{O}-\mathrm{Graph}$ device during a regular dialysis session and the subsequent interdialytic interval. The presence or absence of intradialytic hypertension was adjudicated on the basis of BP responses directly recorded by the MobilO-Graph monitor [3]. The original research hypothesis was that compared with controls, patients with intradialytic hypertension would display higher short-term BP variability during the interdialytic period. This study showed that the average 44 -h interdialytic brachial BP was by $11.0 / 5.4 \mathrm{~mm} \mathrm{Hg}$ higher in cases than in controls (44-h brachial SBP: $143.7 \pm 16.3$ vs. $132.7 \pm 19.3 \mathrm{~mm} \mathrm{Hg}$, $p=0.002$; 44 -h brachial diastolic BP: $84.1 \pm 11.6$ vs. $78.7 \pm$ $12.3 \mathrm{~mm} \mathrm{Hg}, p=0.02$ ) [3]. Contrary to the original hypothesis, 44-h brachial and aortic BP variability assessed with several indices did not significantly differ between groups. Of the 80 between-group comparisons performed, only 4 had unadjusted $p$ values $<0.05$. The lowest $p$ value was 0.01 , suggesting that after correction for multiple hypotheses testing none of the $p$ values would be significant [4]. Even if we were to believe that these significant $p$ values were not a play of chance, $\mathrm{BP}$ variability in those with intradialytic hypertension was in fact smaller, not higher.

The interpretation of the above results requires a careful evaluation of chronobiology of BP variation in those on dialysis. The finding that patients with intradialytic hypertension had an average 44-h interdialytic ambulatory $\mathrm{BP}$ by $11.0 / 5.4 \mathrm{~mm} \mathrm{Hg}$ higher than controls is clinically meaningful is consistent with the results of earlier studies $[1,2]$ and supports our notion that intra- and interdialytic hypertension are like siblings. Accordingly, although BP recordings obtained within the dialysis unit are - in general - imprecise estimates of the actual BP burden assessed with interdialytic home or ambulatory $\mathrm{BP}$ monitoring [5], a rise in BP from pre- to postdialysis of any degree should raise the suspicion of background interdialytic hypertension. Participants with intradialytic hypertension in the study of Bikos et al. [3] were, perhaps, a priori more likely to exhibit interdialytic hypertension. This is due to the definition of intradialytic hypertension applied in case selection that prespecified a postdialysis

Meet the Twins: Intradialytic and

Interdialytic Hypertension
SBP of $>150 \mathrm{~mm} \mathrm{Hg}$. A postdialysis SBP - by itself - at this level predicts interdialytic ambulatory hypertension with a sensitivity of $44.9 \%$ and specificity of $100 \%$ [6].

The higher average of 44-h interdialytic ambulatory BP but the absence of between-group differences in several indices of short-term BP variability - in other words, an increased intercept but blunted circadian amplitude of BP fluctuation - may reflect a "volume-overload BP pattern" on ambulatory BP recordings of patients with intradialytic hypertension in the study of Bikos et al. [3]. This phenotypic signature of volume overload on ambulatory $\mathrm{BP}$ recordings is derived from a post hoc analysis of the Dry-Weight Reduction in Hemodialysis Patients (DRIP) trial [7], in which the chronobiology of BP over the interdialytic interval was analyzed using the trended cosinor model. In the DRIP trial, 100 hypertensive hemodialysis patients were randomized to dry-weight probing via intensified ultrafiltration for 8 weeks, whereas 50 patients did not have their dry-weight probed and served as time controls. Probing of dry-weight in the ultrafiltration group lowered the intercept SBP from baseline to 4 and 8 weeks, steepened the slope of SBP change over time but had no effect on the amplitude of BP variation [7]. Accordingly, if we hypothesize that participants with intradialytic hypertension were volume overloaded, the comparable short-term BP variability between cases and controls or even a lower short-term BP variability in those with intradialytic hypertension in the study of Bikos et al. [3] should not be considered an unexpected finding. The fact that participants with intradialytic hypertension required more intensive antihypertensive drug therapy and were more commonly prescribed calcium-channelblockers $(82.9$ vs. $46.9 \%, p<0.001)$ and centrally acting agents (39.0 vs. $11.3 \%, p<0.001)$ is also supportive of our speculation [3]. Excessive antihypertensive drug use among patients on dialysis is paradoxically associated with inadequate BP control, an association possibly mediated through the interference of intensified antihypertensive drug therapy with dry-weight achievement [8].

The notion that intradialytic hypertension is possibly a marker of volume overload is supported by a growing body of evidence. For example, in the DRIP trial, intradialytic $\mathrm{BP}$ was recorded in all 30 dialysis sessions over the course of the trial and the interrelation of changes provoked by dry-weight reduction in intradialytic BP slopes with changes in 44-h interdialytic BP was explored in a post hoc analysis [9]. At baseline, SBP dropped from preto postdialysis at a rate of $\sim 3 \% / \mathrm{h}(p<0.0001)$. Over the course of the trial, compared to the control group, dryweight probing in the ultrafiltration group steepened the 
intradialytic SBP slopes. The higher the dry-weight reduction achieved during follow-up, the greater was the steepening of intradialytic SBP slopes [9]. Each percent per hour steepening of the intradialytic SBP slope was interrelated with $0.71 \mathrm{~mm} \mathrm{Hg}$ (95\% CI 0.01-1.42, $p=0.048$ ) reduction in 44-h interdialytic SBP [9]. Subsequent studies using bioelectrical impendence analysis showed that patients experiencing a rise in $\mathrm{SBP} \geq 10 \mathrm{~mm} \mathrm{Hg}$ from preto postdialysis had lower weight loss during dialysis and higher extracellular water/total body water ratio relative to patients with stable intradialytic $\mathrm{BP}$ or patients with an intradialytic fall in SBP of $>20 \mathrm{~mm} \mathrm{Hg}$ [10]. Despite the fact that the observational nature of this data cannot provide direct cause-and-effect associations, identification of persistent intradialytic hypertension should raise the suspicion of sub-clinical volume expansion.

Since we believe that intradialytic hypertension and intradialytic hypertension are siblings, and intradialytic hypertension is much easier to identify, we suggest that even with incomplete evidence it may be prudent to treat intradialytic hypertension. The pathophysiology of intradialytic hypertension remains elusive, but in our practice, based on the results of the DRIP trial [9], we probe dryweight to improve overall $\mathrm{BP}$ control. We reason that intradialytic hypertension is a sign of volume overload and therefore improving volume should improve overall BP. The study of Bikos et al. [3], which demonstrates that 44-h interdialytic ambulatory BP was higher by $11.0 / 5.4 \mathrm{~mm} \mathrm{Hg}$ than matched controls, is a call to action. Patients with intradialytic hypertension, as defined in the Bikos et al. [3] study, should at least have a trial of BPlowering through probing of dry-weight. We believe that this improvement in volume and downstream BP may improve the cardiovascular risk of such patients.

\section{Disclosure Statement}

P.I.G. has nothing to disclose. R.A. has the following disclosures: Member data safety monitoring committees: Astra Zeneca, Ironwood Pharmaceuticals Member steering committees of randomized trials: Akebia, Bayer, Janssen, Glaxo Smith Cline, Relypsa, Sanofi and Genzyme US Companies, Member adjudication committees: Bayer, Boehringer Ingelheim, Janssen, Member scientific advisory board or consultant: Celgene, Daiichi Sankyo, Inc., Eli Lilly, Relypsa, Reata, Takeda Pharmaceuticals, USA, ZS Pharma.

\section{Financial Support}

R.A. is supported by NIH 5 R01 HL126903-03.

\section{References}

1 Van Buren PN, Kim C, Toto R, Inrig JK: Intradialytic hypertension and the association with interdialytic ambulatory blood pressure. Clin J Am Soc Nephrol 2011;6:1684-1691.

2 Hompesch C, Ma TW, Neyra JA, Ripley L, Xiao G, Inrig J, Toto R, Van Buren PN: Comparison of ambulatory blood pressure patterns in patients with intradialytic hypertension and hemodialysis controls. Kidney Blood Press Res 2016;41:240-249.

3 Bikos A, Angeloudi E, Memmos E, Loutradis C, Karpetas A, Evi Ginikopoulou E, Panagoutsos S, Pasadakis P, Liakopoulos V, Papagianni A, Sarafidis P: A comparative study of short-term blood pressure variability in he- modialysis patients with and without intradialytic hypertension. Am J Nephrol 2018;48: 295-305.

4 Benjamini Y, Hochberg Y: Controlling the false discovery rate: a practical and powerful approach to multiple testing. J Royal Stat Soc 1995;57:289-300.

5 Agarwal R, Peixoto AJ, Santos SF, Zoccali C: Pre- and postdialysis blood pressures are imprecise estimates of interdialytic ambulatory blood pressure. Clin J Am Soc Nephrol 2006; 1:389-398.

6 Agarwal R, Lewis RR: Prediction of hypertension in chronic hemodialysis patients. Kidney Int 2001;60:1982-1989.
7 Agarwal R: Volume-associated ambulatory blood pressure patterns in hemodialysis patients. Hypertension 2009;54:241-247.

8 Agarwal R: Epidemiology of interdialytic ambulatory hypertension and the role of volume excess. Am J Nephrol 2011;34:381-390.

9 Agarwal R, Light RP: Intradialytic hypertension is a marker of volume excess. Nephrol Dial Transplant 2010;25:3355-3361.

10 Nongnuch A, Campbell N, Stern E, El-Kateb S, Fuentes L, Davenport A: Increased postdialysis systolic blood pressure is associated with extracellular overhydration in hemodialysis outpatients. Kidney Int 2015;87:452457. 